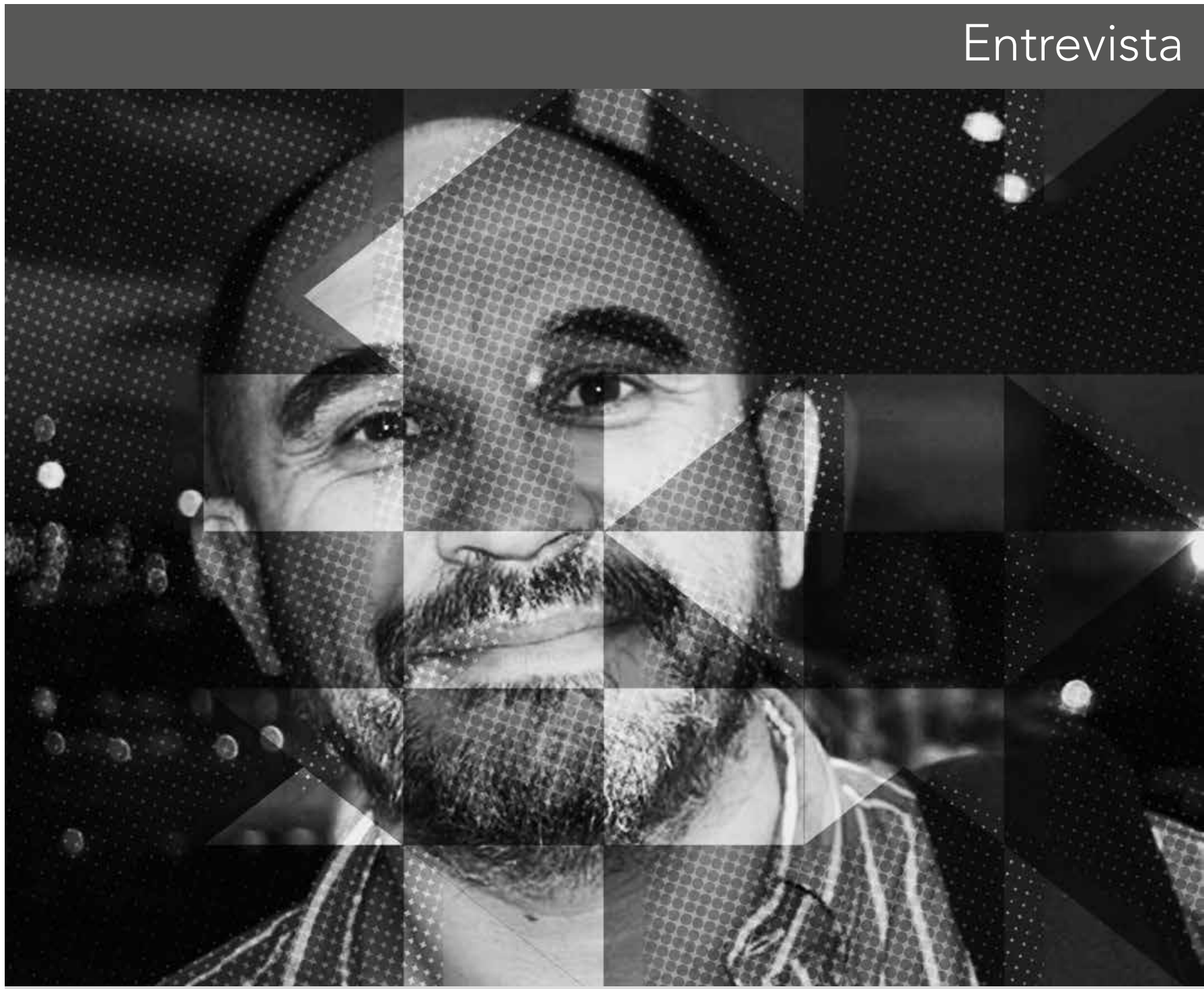

\title{
De la historia como relato, al futuro como posibilidad
}

Entrevista con Pablo Pineau Por Sandra Patricia Ordóñez Castro 
¿Cuál es la importancia de recuperar la memoria histórica desde la escuela?

Por un lado, la enseñanza de la Historia está presente desde el origen de la escuela moderna. El asunto es que el concepto "memoria histórica" combina dos aspectos distintos: la historia, que tiene que ver con reconstruir lo que ha sucedido en el pasado, y la memoria, que hace referencia al acto presente de tener noción del pasado. La memoria es una acción que tiene que ver con el pasado, pero la realiza un sujeto que recuerda en el presente. Entonces la memoria histórica tiene que ver con las formas de vincular pasado y presente. Ahora bien, la escuela puede, o debe, o tiene un lugar muy importante en este proceso de permitir que las nuevas generaciones, los nuevos, los que llegan, los recién llegados, se incorporen en un relato histórico que dé sentido a su existencia, les permita filiar y ocupar un lugar.

Las visiones más tradicionales dirían que hay que transmitirles el pasado para que lo conserven casi intacto. Se proyectan desde una mirada melancólica, decadentista que dice: "Hubo un pasado glorioso, una edad de oro, próceres, hombres y mujeres gloriosas; luego una degradación social, casi inevitable, y entonces la función de la Historia es recordar aquellos prohombres y tratar de establecer los motivos posibles de esta degradación".

Es una versión. También existe otra exactamente contraria, una evolucionista que dice: "Hubo un pasado tremendo en el que sucedían cosas espantosas, pero por suerte el progreso hizo que todo esto desapareciera". En la primera versión, la idea es que cuanto más se parezca el futuro al pasado, mejor. En la segunda es lo contrario: cuanto más distinto sea el futuro del pasado, mejor.

Pero hay otras posiciones que me gustan más: pensar que la relación pasado-presente-futuro es complicada, es de fricción, no es única, es política, es debatible, no cierra. La idea, desde esta perspectiva es romper con esta idea tan moderna del flujo (la imagen del tiempo como un río que fluye continuamente), para ver que hay muchas posiciones y muchas lecturas y muchas formas de encaminarlas: el tiempo, no como una recta sino como un plano en el cual las líneas son curvas. Allí se tendría que ubicar la escuela: en entender la memoria histórica como algo que se construye y que, en tanto se construye, se debate en medio de encuentros, desencuentros y fricciones, que a veces conducen a acuerdos, pero no siempre, porque a veces el consenso no se logra.
¿Contribuye el conocimiento de la historia a prefigurar el futuro con conocimiento de causa? Es decir, ¿la historia se puede trasformar en proyecto?

Sí. Eso es posible. Pero no es obligatorio. Indefectiblemente toda persona se ubica en el tiempo para tener cierto sentido de realidad y, por lo tanto, asume una relación con lo que pasó y con lo que suponemos que va a venir. El papel de la escuela es permitir las relaciones más fructíferas, más productivas, más interesantes, entre pasado, presente y futuro.

¿Desde qué perspectiva debe enseñarse la historia para que su aprendizaje cobre un valor social en el presente?

La clave está en ver el pasado como una construcción histórica, y el presente, no como algo inevitable, sino como el producto de procesos políticos, sociales y culturales protagonizados por hombres y mujeres concretos; más que por hombres y mujeres individuales, por grupos sociales concretos que debatieron en el seno de la sociedad para lograr imponer ciertos proyectos. Cuando digo "imponer" no necesariamente aludo a la fuerza, sino a poder lograr que ciertos proyectos sectoriales lograran ser proyectos políticos en el sentido de abarcar la totalidad.

Entonces, en la enseñanza de la Historia, cuanto más dinámica podamos presentar a la sociedad, cuanto menos lecturas lineales podamos darle a los alumnos, cuanto más visibilicemos los matices, las posiciones, las idas y vueltas, mejor; porque estaremos viabilizando futuros más complejos. El conocimiento de la historia nos permite ver cómo el futuro no está escrito, y que va a depender de nosotros cómo se escriba: cuanto más conozcamos el pasado, más podremos darnos cuenta de que la situación actual no es inevitable, no es la única posible, es producto de luchas, conflictos, posiciones y debates. No lo que tenía que pasar inevitablemente. Así hay una mayor posibilidad de pensar, imaginar y, por ende, producir futuros distintos.

Entonces, ¿más que de una cátedra de historia, podríamos hablar de procesos de formación histórica?

Por un lado, sí creo que tiene que existir la asignatura específica, en especial porque es una forma de producir conocimiento que está más allá de la memorización de hechos, nombres, batallas, nombres de reyes, fechas, nombres de presidentes, etc. Se trata del conocimiento de los procesos sociales. Estamos hablando de las miradas más críticas, más ricas, más potentes, y de la historia social, cultural, política, etc., todas las nuevas líneas 
de la historia que, obviamente, la leen en términos de procesos y no como sucesión de acontecimientos.

Pero, a su vez, la mirada histórica debe atravesar la totalidad del currículo. Todo debe enseñarse con cierta mirada histórica: la ciencia debe enseñarse con perspectiva histórica, para que podamos comprender que lo que hoy sabemos es producto de la historia y que, por ende, no es "lo que es"; es lo que sabemos hoy, que no es lo que antes se sabía y probablemente no va a ser lo que sepamos después. Creo que cuanto más permitamos la "historización" de los saberes y de los procesos, más posibilidades le damos a los alumnos de poder actuar sobre ellos, de no sentirse víctimas de lo que les pasa, sino que puedan ser sujetos capaces de hacer algo para que cambie la situación.

\section{Es decir, potenciamos el advenimiento del sujeto histórico en} un sentido político...

Exactamente. Sujeto histórico somos todos, cualquier ser humano que anduvo por aquí en cualquier condición. El asunto es que cuanta más consciencia tenga un sujeto de que es "histórico", mayor posibilidad va a tener de actuar. Esta es otra finalidad de la enseñanza de la historia: lograr que todos podamos darnos cuenta de nuestra condición como tales, para que podamos potenciarla hacia el futuro.

El sistema tradicional de educación, surgido a fines del siglo pasado, tenía la responsabilidad de difundir contenidos, valores y normas de conducta, destinados a crear vínculos sociales basados en el respeto a las leyes y la lealtad a la nación, por encima de cualquier filiación particular (étnica, religiosa, cultural, de género, etc.). Hoy en día, sin embargo, ya no es posible dar prelación a tales meta-relatos por encima de la subjetividad, ya que es a partir de ella que las personas trazan sus proyectos de vida y hacen sus vínculos relacionales. ¿Cuál es el lugar del sujeto y de la subjetividad en esa formación histórica que veníamos perfilando?

Bueno, yo no diría que ya no hay meta-relatos. Decir que ya no hay meta-relatos es un meta-relato. La idea de que la gente construye a partir de la subjetividad es un meta-relato que estamos dando por "verdad". Yo lo pensaría un poco. Creo que, luego de décadas de cantarle loas a la diversidad, lo cual estuvo muy bien, ha llegado el momento de que nos volvamos a preguntar por la igualdad. Ya sabemos que somos diversos, listo, ya está. Volvamos ahora a preguntarnos en qué somos iguales. Me parece que hay que reestablecer discursos de ese

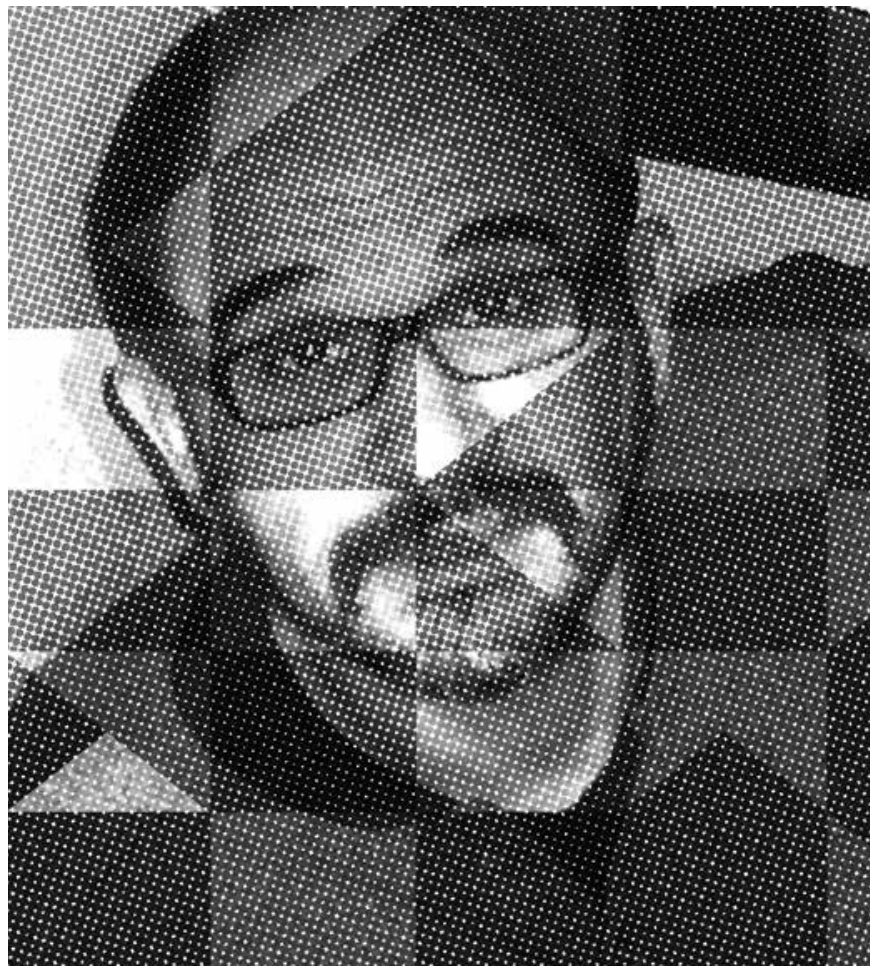

orden: de lo que implica ser humano, independientemente de géneros, razas, religiones, etc.

Hay que volver a pensar en dónde nos encontramos, en qué aspectos tenemos un proyecto en común. "Común” es una palabra que en el debate pedagógico tradicional tenía un peso muy importante. Quizá el concepto se empleaba en un sentido más discriminador o represivo que integrativo, pero me parece que hoy tenemos que volver a pensar qué es lo común, es decir, qué es aquello que hace que mi destino esté unido al de gente que nunca llegaré a conocer. Ha triunfado mucho la idea de que mi destino solo está ligado a la gente cercana a mí, a mi comunidad, a mi vecindario y demás, lo cual es poco. Es chico. Ya va siendo hora de que levantemos la vista y pensemos en qué forma el destino de todos es mi destino.

Bueno... lo que usted plantea es relativo, si pensamos que las subjetividades se tejen también en el ámbito de la globalidad, vamos formando núcleos particulares que son nodos de nuestra historia personal, y ese proceso no está atado a territorios geográficos, sino que es relativo a los vínculos identitarios.. 
Sí, claro. En este momento lo cercano, lo lejano, son relativos. Hemos trascendido la noción topológica de la proximidad y la distancia. La cosa se complica. Y aquí recupero estudios de Bourdieu, de hace ya bastante tiempo, que evidencian que los entramados de redes se hacen más por posición socio-cultural que por cercanía geográfica. La globalización, paradójicamente, llevó a que se cerraran los grupos más en claves sociales y culturales. Me conecto más con la gente que es como yo social y culturalmente, que con los que viven al lado. Pero lo global, lo local, son categorías que para mi gusto deben ser revisadas, porque pedagógicamente se contestan muchas veces desde lugares de sentido común que ameritarían un trabajo más detenido.

Dada esta ambigüedad, y para superar tales instancias de "sentido común", ¿qué categorías propondría usted para perfilar la formación histórica de manera pertinente en el presente?

Bueno, dadas mis raíces, mi marxismo de fundación que critico pero nunca abandoné, no puedo dejar de pensar las sociedades como entidades esencialmente conflictivas, de pensar el conflicto como el gran motor del movimiento social. Por supuesto, cuando digo "conflicto" no lo digo exclusivamente en términos bélicos o violentos, pero sí aludiendo a la diferencia de posiciones. Estamos en una época en que se cantan loas al consenso, lo cual está muy bien, pero olvidamos que muchas veces el consenso es impuesto. Hay un cierto "autoritarismo del conenso", aunque esto suene paradójico. El consenso es deseable, pero muchas veces es imposible y, con frecuencia, tras ese discurso se oculta la intención de mantener el statu quo, diciendo que lo que hay es lo que está consensuado. Entonces, por un lado, me parece que hay recuperar la lógica conflictiva para comprender las sociedades.

Por otra parte, es necesario sumar más voces. El relato sobre la historia sigue estado hegemonizado por el poder. Se cree que hay más hombres que mujeres, más heterosexuales que homosexuales, más urbanos que rurales, más blancos que negros, más sanos que enfermos, etc., etc., y no es así. Pero quienes siguen dominando el relato son unos pocos que cumplen con ciertas condiciones. Esto tiene lógica porque, efectivamente, esos pocos han sido en cierta forma los protagonistas de la historia, pues han tenido el poder, pero tenemos que potenciar discursos en los que los demás, que también estuvieron, no sean simplemente parte de de las multitudes anónimas. Porque se trata de hombres y mujeres con sus propios amores, dolores, madres, padres, afectos, sueños y miedos. Hay que humanizar la historia mucho más, permitir que los alumnos desarrollen empatía con estos sectores y que se den cuenta de que estamos hablando de seres humanos, tal como lo son ellos mismos.

También hay que ver cómo se articula lo global, lo local, lo nacional, lo regional, ver las distintas dimensiones y cómo fueron cambiando históricamente. Basta pensar que en el siglo XVIII muchas personas de América Latina no habían visto una sola imagen de Europa; en el siglo XX quizá no muchos fueron, pero sí vieron imágenes. Entonces hay que historizar esos conceptos. Conflictividad, humanidad y relatividad serían para mí algunas de las pautas para re-pensar, de manera efectiva, la historia como proceso de formación.

¿Sería entonces responsabilidad de la escuela, en relación con la formación histórica, potenciar la transición hacia nuevos imaginarios, instalando capacidades comunicacionales y nuevas comprensiones éticas?

Sí. Aunque lo de la comunicación también es una palabra que yo cuestionaría mucho. Claro que hay que crear estrategias comunicativas, pero los conflictos sociales no son solo problemas de comunicación. Muchas veces la palabra comunicación se nos mete en el discurso para tapar la pregunta por el poder. Todorov dice que en nuestras sociedades toda diversidad oculta una desigualdad, y muchas veces hablar de diversidad es una forma de no hablar de desigualdad. Yo me permito parafrasearlo: en nuestras sociedades toda comunicación implica una forma de poder, y muchas veces hablar de comunicación es una forma de no hablar del poder.

Claro que hay que trabajar en la comunicación, pero teniendo en cuenta que ésta no se trata solo de dos personas con buena voluntad que se encuentran e intercambian, sino que son dos personas y cada una viene con su historia, con su capital cultural y, además, muy difícilmente se encuentran en igualdad de condiciones. Entonces no puedo dejar la comunicación por fuera del debate del poder, porque a veces aparecen discursos sobre la comunicación en los cuales pareciera que pueden suspender esa condición de desigualad y terminan reforzándola.

¿Cómo puede entonces la escuela contribuir a la formación del sujeto histórico, como punto de partida para la emergencia de la identidad y, por lo tanto, de la ciudadanía como instancia mediadora de un proyecto vital?

Lo que pasa es que yo desconfío de la idea de sujetos individuales que construyen proyectos de vida. Hablaría más de pro- 
yectos colectivos. No es el proyecto individual de cada sujeto lo que produce sociedades más justas.

Claro, pero estamos hablando de que hoy las personas asumen consciencia de sí mismos como hacedores de historia y gestionan esa posibilidad a través de redes identitarias...

Claro. Lo que pasa es que me parece a mí que la función de la educación no es que uno encuentre unos iguales, sino que produzca unos iguales. Es decir, en esta sociedad no somos iguales. Yo me voy a encontrar con los que son como yo, no porque sean esencialmente como yo, sino porque son socialmente como yo. El mayor error que puedo pensar es que soy igual solo a ellos. Voy al caso de género porque lo conozco bastante y lo trabajé mucho: durante siglos se planteó que, obviamente, hombres y mujeres éramos absolutamente distintos; tuvo que pasar mucho tiempo para que pudiéramos pensar que sí éramos diferentes, pero que había cosas en las que somos iguales. Si me siento en la idea de "voy a juntarme solo con mis iguales" esto jamás podría tener lugar.

Si planteo la esencialidad de que solamente uno tiene que juntarse con los iguales, no hay forma de contribuir al desarrollo de sociedades más igualitarias. A mí me parece que podemos empezar a juntarnos con los iguales, pero si al terminar el proceso solo me reuní con ellos, la cosa no funcionó. Tengo que lograr que el proceso educativo brinde a los estudiantes la posibilidad de encontrar más con lo que tenemos todos de igual que lo que tenemos de diferentes. Al final, tengo que darme cuenta de que en realidad soy igual al que nunca conocí.

Desde luego. A lo que voy es a que hoy la ciudadanía es entendida en términos de relaciones horizontales y se ha reivindicado el contexto local como escenario para el ejercicio del poder. En esa medida, estaríamos hablando de nuevas dimensiones "territoriales" implicadas en el concepto de ciudadanía...

Los proyectos basados en la territorialidad son amarretes, son poco generosos. Podemos partir de lo cercano, pero tenemos que lograr que los sujetos de un colectivo digan: ¡ $\mathrm{Uy}$ mirá: no me di cuenta de que éramos iguales! Me parece que hay que ampliar el radio de acción de la pedagogía: Tenemos que lograr que se produzcan cosas inimaginables, cosas que no estaban, vínculos nuevos.

En esto coincido con Phillipe Meirieu, pedagogo francés, que cuestiona fuertemente la pedagogía de los intereses., dice que enseñarle a la gente lo que la gente quiere aprender es facilísimo, pero es poco. El tema es enseñarle al otro lo que tiene derecho a aprender. Cualquiera va y te enseña lo que quieres aprender, eso es una tontería, facilísimo. El desafío de la educación es enseñar al otro cosas que ni se le ocurría que le podrían interesar, o que tal vez no le interesan, pero le sirve saberlas. Limitar la pedagogía al interés es fácil, es amarrete, es tacaño, es poco. ¿Tenés un montón de cosas para enseñarles y les vas a enseñar lo que ya querían aprender? Claro, mejor enseñarles eso que no enseñarles nada, pero la verdad es que has sido bien tacaño. No pretendas que te agradezcan por eso. A mí me parece que hay que poder ampliar los escenarios.

Es a ese ampliar los escenarios a donde apuntaba la pregunta: los escenarios, los territorios, no necesariamente físicos, en los que los alumnos puedan (conjugación de poder) crear, trascender los discursos modernos del "ser ciudadano"...

Sí. En ese sentido uno podría plantear una asociación entre la pedagogía y el acto amoroso. Hay dos grandes teorías: una es la del vínculo amoroso como un signo de complementariedad, en el que dos sujetos se encuentran, se unen y se complementan mutuamente. La otra es la de suplementariedad, que platea que el lazo amoroso funciona cuando aparece algo que ninguno de los dos sabía que existía. El vínculo amoroso produce algo que no estaba, algo nuevo, un plus, un suplemento.

Uno puede pensar esta imagen para el acto pedagógico: en la pedagogía, que todo el mundo se comunique, se entienda, está bárbaro, que haya una fluidez absoluta, que todo enganche, que todo articule, etc., pero también podemos pensar que el verdadero acto pedagógico tiene lugar cuando el resultado es algo que ninguno de los protagonistas tenía en la cabeza. Cuando lo que sucedió, ni lo propuso el docente, ni estaba en los intereses del alumno. Un acto pedagógico tiene que ver con el suplemento; cuando aparece algo que no estaba antes. Lo que uno puede ver es que muchas veces ciertas posiciones, que pueden ser muy interesantes, limitan, a pesar del acto pedagógico, a que simplemente aparezca lo que sí se sabía que iba a estar. Eso no está mal. Es mejor que nada, pero es poco.

\section{¿Y cómo se le abre camino a esa impensada posibilidad?}

Esa es la gran pregunta. Primero, creyendo que puede pasar y pensando que, si puede pasar, debe pasar, y tenemos una responsabilidad al respecto. Se debe lograr que los sujetos 
terminen haciendo cosas que nunca creyeron hacer, que puedan ampliar su horizonte de expectativas y no se limiten a lo ya sabido, a que solo aprendan lo que ya saben que les va a servir o que pueden hacer. Es necesario que los docentes claramente confíen en esa posibilidad. Hannah Arendt planteaba, ya en la década del 60 (hace mucho tiempo), lo del acto de amor; pero no de amor a un sujeto concreto, sino a la humanidad. Lo que los griegos llamaron el ágape.

El educador debe amar a la humanidad y creer que ese amor puede hacerla más justa y mejor. En otras palabras, debe confiar en el ágape (son todos bienvenidos, son todos acogidos y todos tienen derecho a una sociedad más justa). Ese es el punto de partida: que crea en una humanidad capaz y obligada a ser mejor, y que se vea con un rol central en ese propósito. Parafraseando a García Márquez, yo diría: Malditas sean las generaciones que se van dejando un mundo más injusto que el que recibieron. Si un educador no confía en su capacidad para producir mayores niveles de justicia, de igualdad, de inclusión, es mejor que empiece a vender cosas en la calle.

¿Es decir, el educador tiene que ser capaz de imaginar y trabajar por la mejor de las posibilidades sin otorgarle una forma específica, sino permitiendo que cobre para cada quién su propio semblante?

Así mismo. Pero la imaginación tiene una contra-cara, que es la memoria, y aquí volvemos a la historia: nadie imagina si no recuerda. Me parece a mí que cuanto más podamos recordar, mayores niveles imaginativos podremos alcanzar. La función de la historia es poner a disposición de los que vienen la mayor cantidad de recuerdos, para que imaginen las cosas futuras. Ahí, en ese pasaje, entre recuerdo-sujeto-imaginación, es donde debe inscribirse la posibilidad de cierta consciencia histórica.

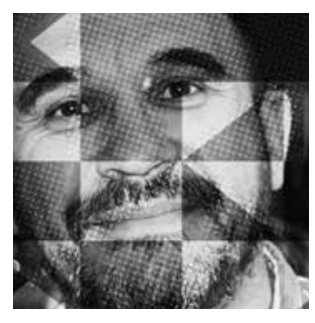

